\title{
Depression in Women Migrants Living in Slums in North India
}

\author{
Ram Lakhan ${ }^{1}$ Manoj Sharma² \\ ${ }^{1}$ Department of Health and Human Performance, Berea College, \\ Berea, Kentucky, United States \\ ${ }^{2}$ Department of Environmental and Occupational Health, University \\ of Nevada, Las Vegas, United States
}

J Neurosci Rural Pract 2021;12:223-223.

We have read the above-mentioned article with great interest. ${ }^{1}$ Mental health problems have been on an upward incline globally. Among all mental health issues, depression is affecting the largest proportion of the population. According to the World Health Organization (WHO), approximately 264 million people around the world experience depression. Annually, over 800,000 people commit suicide due to sequelae of depression. Between $76 \%$ and $85 \%$ of people with depression live in low- and middle-income countries. ${ }^{2}$ Poor and women living either in developed or developing nations bear the greatest burden of depression. ${ }^{3}$ The outbreak of COVID-19 has created fear and panic around the world. The public health measures taken in India to contain the virus from the further spread in the population have adversely affected the poorest people the most and widened disparities. ${ }^{4}$ The uncertainty, loss of income, fear of death, isolation, and amplified marginalization has mounted in the population, which has resulted in higher susceptibility for mental health problems among the poor and vulnerable populations. This above-mentioned cross-sectional study ${ }^{1}$ estimates the prevalence of depression and anxiety in migrants living in a sample of slum areas.

In this survey, the prevalence of depression was found to be $3.5 \%$ (95\% CI: $0.95-6.05$ ) and anxiety $2.5 \%$ (95\% CI: $0.34-$ 4.66 ) in the participants who included $83 \%$ of women in the sample. ${ }^{1}$ This survey was conducted over a span of 1 month from June 12 to July $11,2020 .{ }^{1}$ In another study, in the general population in India, the rates of severe depression and anxiety were observed to be quite high during COVID-19. ${ }^{5}$ Besides the short duration and methodological limitations of this study, ${ }^{1}$ myriad factors may be responsible for an underestimate of the prevalence. By June 2020, the restrictions placed due to COVID-19 had been eased in India, awareness on the issue had increased, and people had started adjusting to the situation.

Address for correspondence Ram Lakhan, Department of Health and Human Performance, Berea College, Berea, Kentucky, United States (e-mail: ramlakhan15@gmail.com).
Thus, this study ${ }^{1}$ captured estimates when the population had adjusted to the circumstances. The anxiety levels understandably reduce with more information about any calamity, which in this case was the COVID-19 pandemic. Further, increased social cohesion that people started building around them, and the reduced rate of seasonal depression, may have contributed to lower estimates. In relation to the national estimates of depression, ${ }^{6}$ this study indicates that women of migrant families living in slum areas are having a disproportionately higher burden of depression in India. Hence, further research is needed to identify the causes of higher rates of depression, and strategic public health interventions need to be planned to address the concern. Such public health measures should include both educational interventions and policy-level supports.

\section{Conflict of Interest}

None declared.

\section{References}

1 Choudhari R. Prevalence of depression and anxiety during the COVID-19 Pandemic among the migrants of urban slums in North India. J Neurosci Rural Pract 2021;12:153-158

2 World Health Organization (WHO). Depression. Accessed November 27, 2020 at: https://www.who.int/health-topics/ depression\#tab=tab_1

3 Liu Q, He H, Yang J, Feng X, Zhao F, Lyu J. Changes in the global burden of depression from 1990 to 2017: findings from the global burden of disease study. J Psychiatr Res 2020; 126(126):134-140

4 Mukherjee S. Disparities, desperation, and divisiveness: coping with COVID-19 in India. Psychol Trauma 2020;12(6):582-584

5 Verma S, Mishra A. Depression, anxiety, and stress and socio-demographic correlates among general Indian public during COVID-19. Int J Soc Psychiatry 2020;66(8):756-762

6 Gururaj G, Varghese M, Benegal V, et al. National Mental Health Survey of India, 2015-16: Summary. Accessed December 17, 2020 at: http://www.indianmhs.nimhans.ac.in/Docs/Summary.pdf
DOI https://doi.org/

$10.1055 / \mathrm{s}-0041-1726624$ ISSN 0976-3147
(C2021. Association for Helping Neurosurgical Sick People.

This is an open access article published by Thieme under the terms of the Creative Commons Attribution-NonDerivative-NonCommercial-License, permitting copying and reproduction so long as the original work is given appropriate credit. Contents may not be used for commercial purposes, or adapted, remixed, transformed or built upon. (https://creativecommons.org/licenses/by-nc-nd/4.0/).

Thieme Medical and Scientific Publishers Pvt. Ltd. A-12, 2nd Floor, Sector 2, Noida-201301 UP, India 